\title{
The effect of superhydrophobic coating on the electrochemical behavior of carbon steel in chloride and hydrogen sulfide-chloride environments
}

\author{
V.I. Vigdorovich, ${ }^{+1}$ L.E. Tsygankova, ${ }^{1,2 *}$ A.M. Emel'yanenko, ${ }^{3}$ \\ M.N. Uryadnikova ${ }^{2}$ and E.Yu. Shel ${ }^{4}$
}

${ }^{1}$ All-Russian Scientific Research Institute of Use of Machinery and Oil Products, NovoRubezhnyi per., 28, Tambov, 392022, Russian Federation

${ }^{2}$ Derzhavin State University, ul. Internatsyonalnaya, 33, Tambov, 392000, Russian

Federation

${ }^{3}$ A.N. Frumkin Institute of Physical Chemistry and Electrochemistry, Russian Academy of Sciences, Leninsky pr. 31, 119071 Moscow, Russian Federation

${ }^{4}$ Tambov State Technical University, ul. Sovetskaya, 106, Tambov, 392000, Russian

Federation

*E-mail: vits21@mail.ru

\begin{abstract}
Corrosion and kinetics of electrode processes on St3 steel with a superhydrophobic coating based on laser surface texturing followed by hydrophobization with fluoroxysilane (wetting angle $165 \pm 2^{\circ}$, rolling angle $3 \pm 1^{\circ}$ ) have been studied in a highly mineralized chloride medium $(50 \mathrm{~g} / \mathrm{L} \mathrm{NaCl})$ in the absence and presence of an additive of hydrogen sulfide $(400 \mathrm{mg} / \mathrm{L})$. Similar studies were conducted with uncoated electrodes. The influence of a duration of an exposure of the electrodes in a solution (0.25-96 hours) on kinetics of electrode processes and corrosion rate of steel is considered. In the absence of hydrogen sulfide, a presence of a superhydrophobic coating on steel causes a decrease in the corrosion rate by 67,13 , and 2 times after $0.25,24$, and 48 hours of exposure in a chloride solution. In time, the cathodic process slows down and the anodic one accelerates, especially in a case of electrodes with a hydrophobic coating. In the presence of hydrogen sulfide in a chloride solution, steel with a superhydrophobic coating is characterized by more than an order of magnitude low corrosion rate, compared with unprotected samples during a 96-hour exposure of the electrodes. In this case, there is a slowdown in the anodic reaction and acceleration of the cathodic one compared to the solution without hydrogen sulfide. The corrosion process proceeds with anodic control.
\end{abstract}

Keywords: steel, superhydrophobic coating, corrosion rate, kinetics, hydrogen sulfide, electrode process.

Received: December 9, 2019. Published: February 3, 2020

doi: $\underline{10.17675 / 2305-6894-2020-10-1-10}$ 


\section{Introduction}

In recent decades, systematic studies of hydrophobization and superhydrophobization of metals are carried out to increase their corrosion resistance [1-9]. Coatings are considered that increase the angle of wetting with water to a range of $\geq 150^{\circ}$ and reduce the angle of rolling to $\sim 10^{\circ}$. The greatest attention is paid to the application of superhydrophobic protective coatings, allowing to increase the wetting angle to $165-171^{\circ}$. One of the main mechanisms of the protective action of such coatings under conditions of electrochemical corrosion is related to the fact that they prevent water molecules from being supplied to the metal surface, the presence of which is necessary for partial electrode reactions to occur. This mechanism was considered in more detail in [10], and other mechanisms conditional on the superhydrophobic state of the surface - in [11].

In [12], the results of a study of the corrosion and electrochemical behavior of St3 carbon steel with a superhydrophobic surface layer in a $0.5 \mathrm{M} \mathrm{NaCl}$ solution are presented. The effect of two types of superhydrophobic coating was considered. To obtain a coating of type I, the metal surface was textured with IR laser radiation nanosecond duration with subsequent chemisorption of methoxy-\{3-[(2,2,3,3,4,4,5,5,6,6,7,7,8,8,8-pentadecafluorooctyl)-oxy]propyl $\}$ silane from a $n$-decane solution (MAF). To obtain a type II coating, a nanosized composite layer consisting of Aerosil nanoparticle aggregates coated with the same hydrophobic agent was additionally applied on the type I coating. The contact angle on the initial steel sample was $85.3 \pm 2.7^{\circ}$, whereas that on the superhydrophobic samples of both types was $168 \pm 1.5^{\circ}$. It was shown that upon reaching a steady state (after $72 \mathrm{~h}$ ), the corrosion rate of steel with a superhydrophobic coating of both types is reduced by $23 \pm 3$ times compared with unprotected samples. The corrosion potential of protected steel immediately after immersing the electrodes in the solution is $0.140 \mathrm{~V}$ ( $E_{\text {cor }}$ of unprotected steel is $\left.-0.420 \mathrm{~V}\right)$, when a stationary state is reached, its value is close to $-0.6 \mathrm{~V}$. The steel corrodes in the active state with cathodic control.

It is of interest to study the protective properties of superhydrophobic coatings on St3 steel in hydrogen sulfide environments that are widely encountered in oil production and oil refining.

The aim of this work is to study the corrosion and electrochemical behavior of carbon steel with a superhydrophobic coating of a different type than in [12], in a chloride solution in the absence and presence of hydrogen sulfide additive.

\section{Experimental}

The electrochemical and corrosion behavior of St3 carbon steel with a superhydrophobic coating was studied in a $\mathrm{NaCl}$ solution $(50 \mathrm{~g} / \mathrm{L})$ in the absence and presence of $\mathrm{H}_{2} \mathrm{~S}$ additive $(400 \mathrm{mg} / \mathrm{L})$. The superhydrophobic coating was applied in the Laboratory of Surface Forces at the Institute of Physical Chemistry and Electrochemistry, Russian Academy of Sciences, to samples pressed into a fluoroplastic frame with a working surface area close to $0.5 \mathrm{~cm}^{2}$. To obtain a coating, the working surface was textured with a 
nanosecond IR laser with the following laser processing parameters: pulse duration $50 \mathrm{~ns}$, pulse frequency $20 \mathrm{kHz}$, peak pulse power $0.95 \mathrm{~mJ}$, linear laser beam rate $50 \mathrm{~mm} / \mathrm{s}$, scanning density 150 lines per $\mathrm{mm}$. Immediately after texturing with the indicated parameters, the surface showed super hydrophilic properties - a drop of water when it touched such a surface instantly spread into a thin film. To impart superhydrophobic properties to the surface, the surface energy of the formed texture was lowered by chemisorption of the hydrophobizing agent $\mathrm{CF}_{3}\left(\mathrm{CF}_{2}\right)_{6}\left(\mathrm{CH}_{2}\right) \mathrm{O}\left(\mathrm{CH}_{2}\right)_{2} \mathrm{C}\left(\mathrm{OCH}_{3}\right)_{3}$ from the vapor phase, followed by drying of the resulting coating at $130^{\circ} \mathrm{C}$ for 1 hour. The wetting angle on the obtained superhydrophobic samples was $165 \pm 2^{\circ}$, and the rolling angle for droplets with a volume of $15 \mu \mathrm{L}$ was $3 \pm 1^{\circ}$. The samples under study (due to design features) were not subjected to ultraviolet irradiation in the presence of ozone plasma. Such a treatment leads to an increase in the number of chemisorption-active centers in the form of hydroxyl or carboxyl surface groups and promotes chemisorption of a hydrophobic agent on them [2]. This was an additional interest in testing the protective abilities of coatings in the proposed conditions. Polarization measurements were measured on electrodes without a protective coating and with a protective coating in the studied media using an IPC-Pro potentiostat (produced by A.N. Frumkin Institute of Physical Chemistry and Electrochemistry, RAS) by the potentiodynamic method with a potential scan rate of $0.66 \mathrm{mV} / \mathrm{s}$. The potentials were measured with respect to the saturated silver/silver chloride electrode and were recalculated to the standard hydrogen scale. The counter electrode is a smooth platinum. The studies were carried out at room temperature in aerated solutions in a three-electrode cell with separated anode and cathode spaces on electrodes made of carbon steel St3 with a chemical composition, mass \%: C $-0.20 ; \mathrm{Mn}-0.50 ; \mathrm{Si}-0.15$; $\mathrm{P}-0.04 ; \mathrm{S}-0.05 ; \mathrm{Cr}-0.30 ; \mathrm{Ni}-0.20 ; \mathrm{Cu}-0.20, \mathrm{Fe}-98.36$. Polarization curves were measured each time on a new electrode with a protective coating after appropriate exposure in the test solution (day, two, three days).

\section{Results and discussion}

\section{Chloride media}

Uncoated steel after 15 minutes of immersion into $\mathrm{NaCl}$ solution is characterized by the corrosion potential $E_{\text {cor }}$ equal to $-0.46 \mathrm{~V}$ (Figure1). The magnitude of $\mathrm{E}_{\mathrm{cor}}$ of steel with a superhydrophobic coating is close to $-0.15 \mathrm{~V}$ (Figure 1). The polarization curves (PC) in the absence of coating have slope coefficients of the linear Tafel sections $\mathrm{d} E_{\mathrm{a}} / \mathrm{d} l g \mathrm{i}_{\mathrm{a}}$ and $\mathrm{d} E_{\mathrm{c}} / \mathrm{d} l g i_{\mathrm{c}}$ equal to 39 and $100 \mathrm{mV}$, respectively, and the corrosion rate $i_{\text {cor }}$, according to the extrapolation of the PC to the corrosion potential, is $0.40 \mathrm{~A} / \mathrm{m}^{2}$. Thus, the corrosion rate of steel with a hydrophobic coating is reduced by a factor of 67 , the anodic metal ionization process is inhibited, and the cathodic oxygen depolarization process, on the contrary, is facilitated compared to unprotected steel (Figure 1). Steel corrosion is limited by the anode process. 


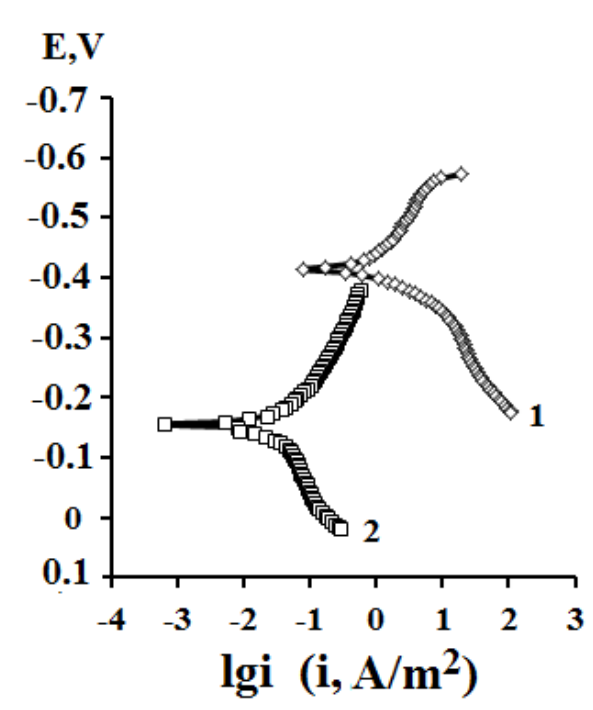

Figure 1. Polarization curves measured on a steel electrode without coating (1) and with superhydrophobic coating (2) after exposure to $\mathrm{NaCl}$ solution for $0.25 \mathrm{~h}$.

After a 24-hour exposure of the electrode with the protective coating in the same corrosive medium, the corrosion potential sharply shifts to the region of more negative potentials, assuming a value of $-0.48 \mathrm{~V}$. The $E_{\text {cor }}$ of unprotected steel is changed less significantly $(-0.56 \mathrm{~V})$ (Figure 2$)$. The Tafel slope coefficient of the initial linear section of the anode curve remains virtually unchanged, while the cathode slope coefficient decreases to $80 \mathrm{mV}$ on uncoated steel. On coated steel, the values of $\mathrm{d} E_{\mathrm{a}} / \mathrm{d} l g \mathrm{i}_{\mathrm{a}}$ and $\mathrm{d} E_{\mathrm{c}} / \mathrm{d} l g \mathrm{i}_{\mathrm{c}}$ are 38 and $79 \mathrm{mV}$, respectively. The anodic metal ionization process is still inhibited compared to unprotected steel, although to a lesser extent than at the moment of immersion. The value of $i_{\text {cor }}$ of coated steel is 13 times less than in the absence of coating, and increases, compared with the value at the initial stage, to $0.012 \mathrm{~A} / \mathrm{m}^{2}$. The contact angle after 24 hours of exposure is reduced to $141^{\circ}$.

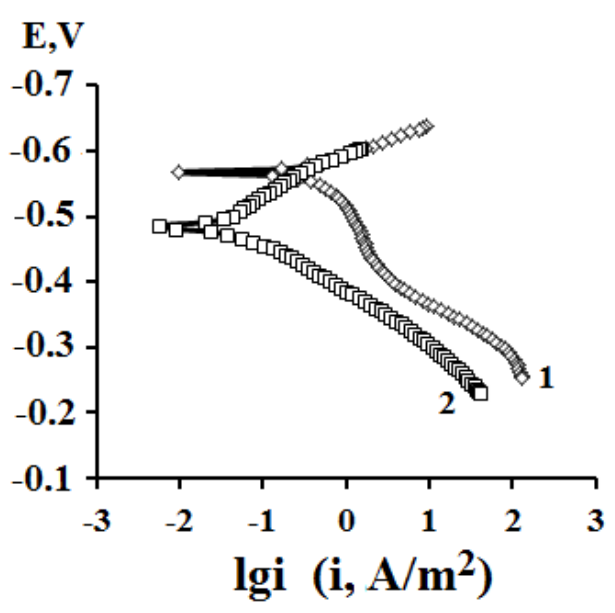

Figure 2. Polarization curves measured on a steel electrode without coating (1) and with superhydrophobic coating (2) after exposure to $\mathrm{NaCl}$ solution for $24 \mathrm{~h}$. 
An increase in the duration of the corrosive action of medium up to $48 \mathrm{~h}$ does not qualitatively change the situation in the case of uncoated steel compared to the previous days, and for steel with a coating $i_{\text {cor }}$ increases to $0.056 \mathrm{~A} / \mathrm{m}^{2}$ and $E_{\text {cor }}$ continues to shift to the region of more negative potentials, reaching $-0.58 \mathrm{~V}$ (Figure 3 ). The anode curves in the region of active dissolution practically coincide for both electrodes near $E_{\text {cor }}$, and the cathodic process on the hydrophobic electrode is inhibited. Moreover, on the anode curve at $\mathrm{E}=-0.55 \mathrm{~V}$, a transition to the limiting current section is observed, which, starting from $0.42 \mathrm{~V}$, acquires a gentle course. The wetting angle is $133^{\circ}$ (Figure 4). The value of $i_{\text {cor }}$ of coated steel is 2 times lower compared to an unprotected electrode.

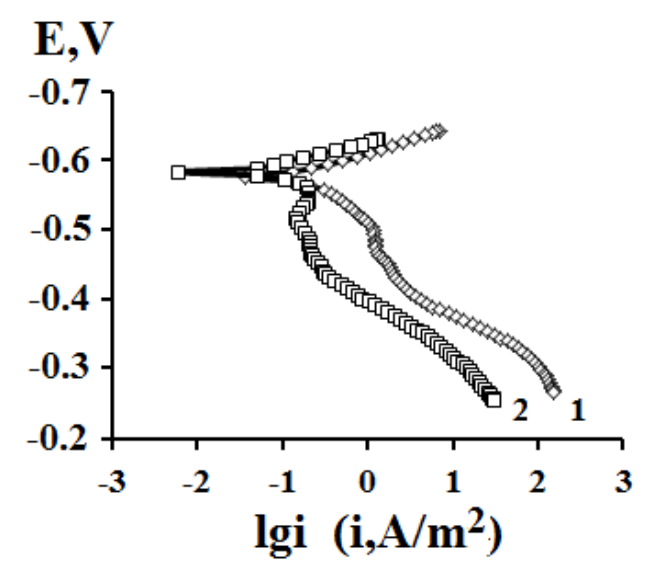

Figure 3. Polarization curves measured on a steel electrode without coating (1) and with superhydrophobic coating (2) after exposure to $\mathrm{NaCl}$ solution for $48 \mathrm{~h}$.
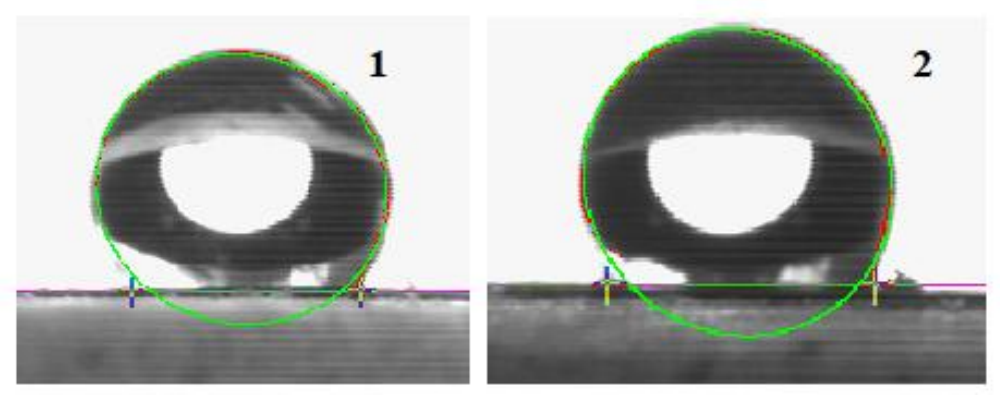

Figure 4. The values of the contact angle on the electrode with superhydrophobic coating after exposure in a chloride solution for $24 \mathrm{~h}(1)$ and $48 \mathrm{~h}(2): 1-141^{\circ}, 2-133^{\circ}$.

After 72 hours, the values of $i_{\text {cor }}$ of the electrodes with and without coating are almost the same (Figure 5). Their $E_{\text {cor }}$ are respectively -0.60 and $-0.57 \mathrm{~V}$. On the coated electrode, the anodic process in the region of active dissolution is somewhat facilitated and the cathodic one is inhibited compared to an uncoated electrode. On the anode curve of the hydrophobic electrode at $E=-0.53 \mathrm{~V}$, a transition to the limiting current region is observed, as in the 48-hour exposure, which, starting from $-0.42 \mathrm{~V}$, acquires a gentle course. The contact angle on the coated electrode in some parts of the surface is $128^{\circ}$, in others $-80^{\circ}$ (Figure 6 ). In the latter case, corrosion products are visualized on the surface. 


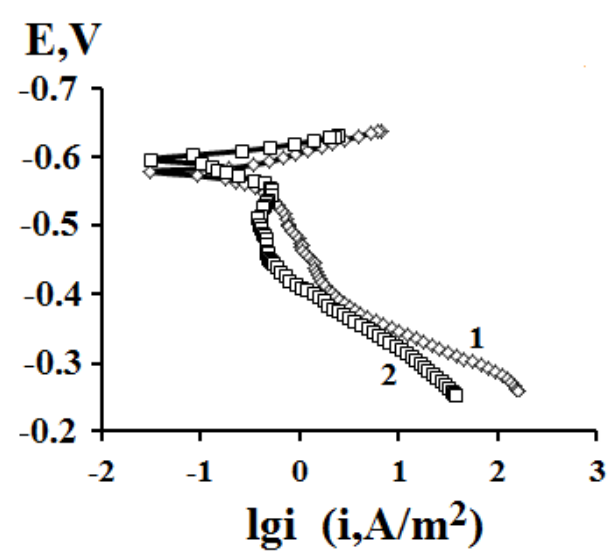

Figure 5. Polarization curves measured on a steel electrode without coating (1) and with superhydrophobic coating (2) after exposure to $\mathrm{NaCl}$ solution for $72 \mathrm{~h}$.

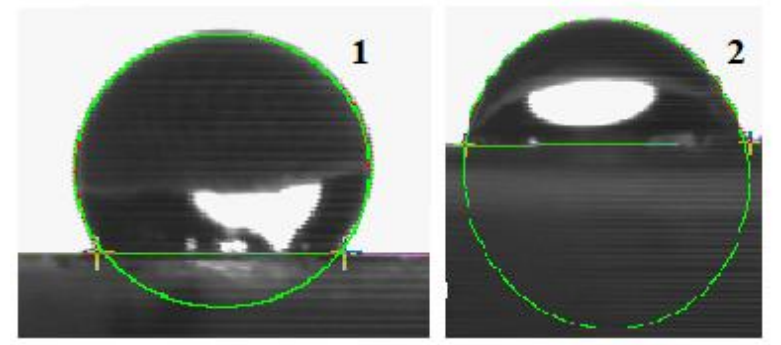

Figure 6. The values of the contct angle at different parts of the surface of the electrode with a superhydrophobic coating after exposure to the chloride solution for 72 hours: $1-128^{\circ}, 2-80^{\circ}$.

Thus, it is obvious that due to the lack of treatment of the electrodes before hydrophobization with ultraviolet radiation, the superhydrophobic coating studied in this work turned out to be less durable than in the presence of such treatment [2]. The bond of the hydrophobic layer with the substrate when the electrode was in the chloride medium was weakened over time and after 72 hours rather extensive areas with a broken coating and a contact angle reduced to $80^{\circ}$ were formed, where corrosion products were clearly fixed.

\section{Chloride-hydrogen sulfide environments}

Let us compare the behavior of uncoated steel and with a superhydrophobic coating in a solution with a composition of $50 \mathrm{~g} / \mathrm{L} \mathrm{NaCl}+400 \mathrm{mg} / \mathrm{L} \mathrm{H}_{2} \mathrm{~S}$. The polarization curves measured on uncoated steel are shown in Figure 7, which shows that with an increase in the exposure time of the electrodes in solution up to $48 \mathrm{~h}$, the anodic reaction accelerates, and the cathodic reaction slows down. Further exposure to the solution up to 72 and 96 hours is accompanied by a slowdown of the anode reaction and acceleration of the cathode one. Correspondingly, the corrosion potential shifted to the negative region during the first two days, and to the positive region on days 3 and 4 . This situation can be explained by the initial acceleration of the metal ionization process due to the participation of $\mathrm{H}_{2} \mathrm{~S}$ and $\mathrm{HS}^{-}$adsorbed 
on the surface and its subsequent inhibition by the surface film of sulfide corrosion products formed over time, as it is usually observed in hydrogen sulfide media [13, 14].

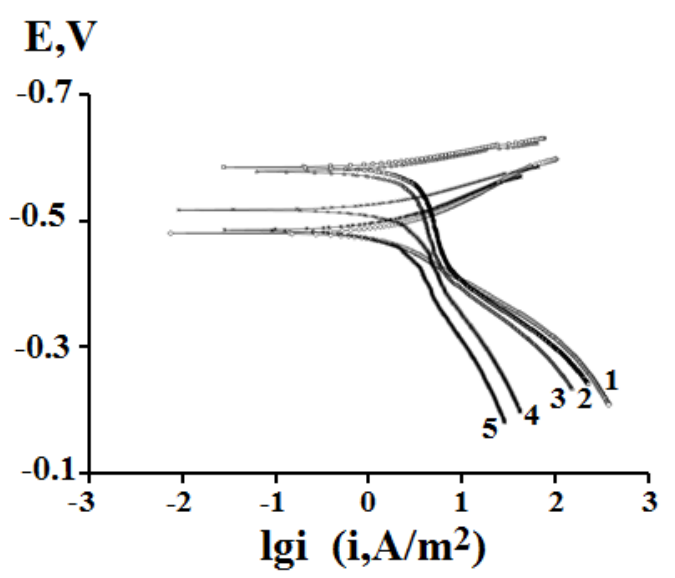

Figure 7. Polarization curves measured on a steel electrode without coating after exposure to $\mathrm{NaCl}+400 \mathrm{mg} / \mathrm{L} \mathrm{H}_{2} \mathrm{~S}$ solution for, h: $1-0,25,2-24,3-48,4-72,5-96$.

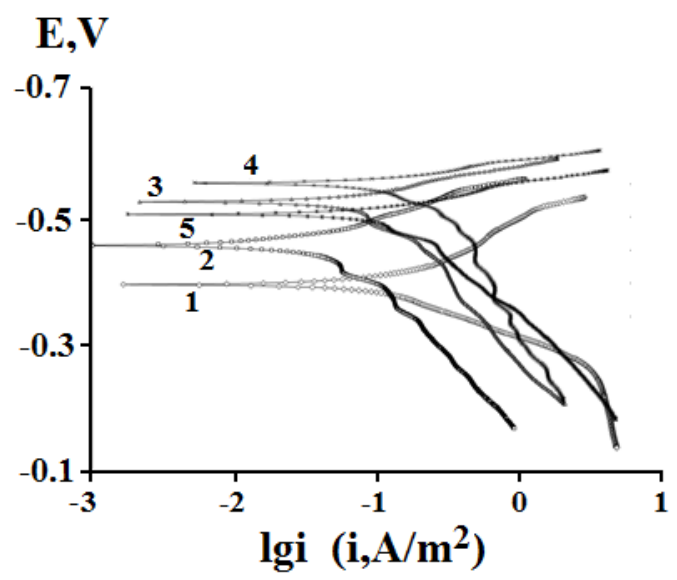

Figure 8. Polarization curves measured on a steel electrode with superhydrophobic coating after exposure to $\mathrm{NaCl}+400 \mathrm{mg} / \mathrm{L} \mathrm{H}_{2} \mathrm{~S}$ solution for, h: $1-0,25,2-24,3-48,4-72,5-96$.

In the presence of a superhydrophobic coating on the electrode surface, an increase in the exposure time of the electrodes in solution up to 3 days is accompanied by an acceleration of the anode process and inhibition of the cathode one. On the 4th day, the anodic reaction slows down, and the cathodic reaction accelerates (Figure 8). Accordingly, $E_{\text {cor }}$ is shifted to the negative region within 3 days, and on the 4th day - to the positive one. The reason for this behavior is the same as in the case of unprotected electrodes, however, the presence of a superhydrophobic coating, obviously, helps to slow down the formation of a film of sulfide corrosion products, therefore, the inhibition of metal ionization begins on the 4th day of the electrode being in solution. Corrosion currents on electrodes with superhydrophobic coating are an order of magnitude or more lower than those on the uncoated electrodes (Table 1). 
Table 1. Kinetic parameters of the St3 electrode without and with a hydrophobic coating in a solution of $50 \mathrm{~g} / \mathrm{L} \mathrm{NaCl}+400 \mathrm{mg} / \mathrm{L} \mathrm{H}_{2} \mathrm{~S}$.

\begin{tabular}{c|cccc|cccc}
\hline \multirow{2}{*}{$\begin{array}{c}\text { The time of } \\
\text { exposure, } \mathbf{h}\end{array}$} & \multicolumn{3}{|c|}{ Electrode without coating } & \multicolumn{4}{c}{ Electrode with coating } \\
\cline { 2 - 8 } & $\boldsymbol{b}_{\mathbf{a}}, \mathbf{m V}$ & $\boldsymbol{b}_{\mathbf{c}}, \mathbf{m V}$ & $\boldsymbol{i}_{\text {cor }}, \mathbf{A} / \mathbf{m}^{\mathbf{2}}$ & $\boldsymbol{E}_{\text {cor }}, \mathbf{V}$ & $\boldsymbol{b}_{\mathbf{a}}, \mathbf{m V}$ & $\boldsymbol{b}_{\mathbf{c}}, \mathbf{m V}$ & $\boldsymbol{i}_{\text {cor }}, \mathbf{A} / \mathbf{m}^{\mathbf{2}}$ & $\boldsymbol{E}_{\text {cor }}, \mathbf{V}$ \\
\hline 0.25 & 62 & 100 & 1.27 & -0.48 & 60 & 90 & 0.100 & -0.39 \\
24 & 70 & 30 & 1.11 & -0.59 & 70 & 69 & 0.027 & -0.45 \\
48 & 70 & 40 & 1.12 & -0.58 & 60 & 41 & 0.047 & -0.52 \\
72 & 62 & 40 & 1.14 & -0.52 & 71 & 32 & 0.060 & -0.55 \\
96 & 62 & 54 & 1.14 & -0.49 & 78 & 52 & 0.050 & -0.50 \\
\hline
\end{tabular}

The preservation of the protective effect by a superhydrophobic coating in a chloride medium in the presence of hydrogen sulfide for a longer time than in its absence is most likely due to the formation of sulfide corrosion products that isolate wetted areas,being present according to some researchers [15], on a superhydrophobic surface.

Let us evaluate the effect of the presence of $\mathrm{H}_{2} \mathrm{~S}$ in a $\mathrm{NaCl}$ solution on the behavior of a hydrophobic coated electrode. At the initial stage of corrosion $(0.25 \mathrm{~h})$, the presence of $\mathrm{H}_{2} \mathrm{~S}$ accelerates the anodic reaction and slows down the cathodic process on the hydrophobic coated electrode compared to its behavior in the absence of hydrogen sulfide. At the same time, $E_{\text {cor }}$ shifts to the region of more negative potentials. The corrosion process proceeds with cathodic control (Figure 9).

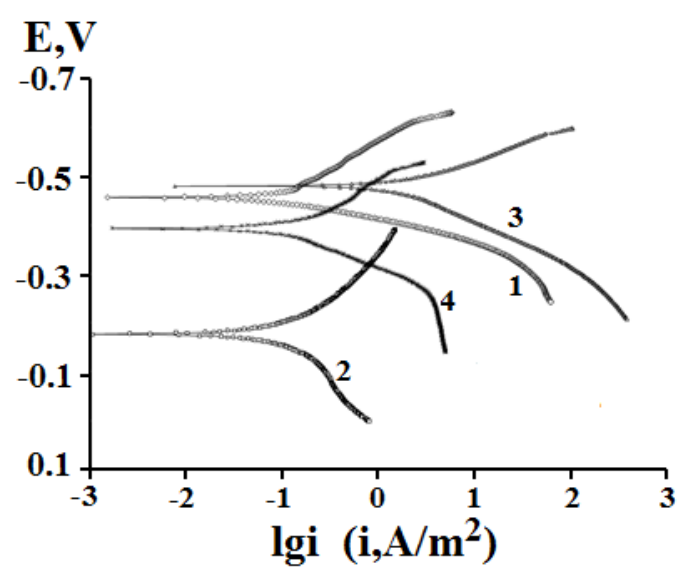

Figure 9. Polarization curves measured on a steel electrode after 0.25 hours of exposure in a $\mathrm{NaCl}$ solution without $(1,2)$ and with $400 \mathrm{mg} / \mathrm{L} \mathrm{H}_{2} \mathrm{~S}(3,4)$ in the absence $(1,3)$ and in the presence of a hydrophobic coating on the electrode surface $(2,4)$.

When the electrode with a hydrophobic coating is exposed for 24-96 hours in a solution with $\mathrm{H}_{2} \mathrm{~S}$, the anodic reaction slows down and the cathodic one accelerates as compared to the solution without hydrogen sulfide. At the same time, $E_{\text {cor }}$ shifts to the 
region of more positive potentials in the presence of $\mathrm{H}_{2} \mathrm{~S}$. The corrosion process proceeds with anodic control.

\section{Conclusion}

In a highly mineralized chloride medium $(50 \mathrm{~g} / \mathrm{L} \mathrm{NaCl})$, the superhydrophobic coating under study (contact angle $165^{\circ}$ ) causes a decrease in the corrosion rate 67,13 , and 2 fold after $0.25,24$, and 48 hours of exposure. In this case, the contact angle decreases to 141 , 133 , and in the latter case, 128 and $80^{\circ}$, respectively, in different parts of the surface when visualizing corrosion products.

At the initial stage of corrosion $(0.25 \mathrm{~h})$, the presence of $\mathrm{H}_{2} \mathrm{~S}$ in the chloride medium accelerates the anodic reaction and slows down the cathodic process on the electrode with a hydrophobic coating in comparison with a solution without $\mathrm{H}_{2} \mathrm{~S}$. At the same time, $E_{\text {cor }}$ shifts to the region of more negative potentials. The corrosion process proceeds with cathodic control.

When the electrode with a hydrophobic coating is exposed for 24-96 hours in the solution with $\mathrm{H}_{2} \mathrm{~S}$, the anodic reaction slows down and the cathodic one accelerates, compared with a solution without hydrogen sulfide. At the same time, $E_{\text {cor }}$ shifts to the region of more positive potentials. The corrosion process proceeds with anodic control.

The corrosion rate of steel with a superhydrophobic coating in the solutions containing $400 \mathrm{mg} / \mathrm{L} \mathrm{H}_{2} \mathrm{~S}$ is an order of magnitude or more lower than without coating during 96 hours of exposure in solution.

\section{Acknowledgments}

This work was supported by the Russian Science Foundation, grant No. 18-16-00006. The experimental results were obtained using the equipment of the Center for Collective Use of Scientific Equipment of TSU named after G.R. Derzhavin.

\section{References}

1. L.B. Boinovich and A.M. Emel'yanenko, Hydrophobic materials and coatings: principles of design, properties and applications, Russ. Chem. Rev., 2008, 77, no. 7, 583-600. doi: 10.1070/RC2008v077n07ABEH003775

2. L. Boinovich and A. Emel'yanenko, A wetting experiment as a tool to study the physicochemical processes accompanying the contract of hydrophobic and superhydrophobic materials with aqueous media, Adv. Colloid Interface Sci., 2012, 179, 133-141. doi: 10.1016/j.cis.2012.06.010

3. L.B. Boinovich, K.A. Emel'yanenko, A.G. Domantovsky and A.M. Emel'yanenko, Laser tailoring the surface chemistry and morphology for wear, scale and corrosion resistant superhydrophobic coatings, Langmuir, 2018, 34, no. 24, 7059-7066. doi: 10.1021/acs.langmuir.8b01317 
4. L.B. Boinovich, S.V. Gnedenkov, D.A. Alpysbaeva, V.S. Egorkin, A.M. Emel'yanenko, S.L. Sinebryukhov and A. K. Zaretskaya, Corrosion resistance of composite coatings on low-carbon steel containing hydrophobic and superhydrophobic layers in combination with oxide sublayers, Corros. Sci., 2012, 55, 238-245. doi: $10.1016 /$ j.corsci.2011.10.023

5. D.A. Alpysbaeva, D.B. Vershok, A.M. Emel'yanenko, O.V. Batishchev, Yu.I. Kuznetsov and L.B. Boinovich, Superhydrophobization of low-carbon steel by surface coatings, Korroz.: mater., zashch. (Corrosion: materials, protection), 2013, no. 8, 42 (in Russian).

6. K.A. Emel'yanenko, N.A. Sanzharovsky, E.V. Chulkova, A.A. Ganne, A.M. Emel'yanenko and L.B. Boinovich, Superhydrophobic corrosion resistant coatings for copper via IR nanosecond laser processing, Mater. Res. Express, 2018, 5, no. 11, Article ID 115001. doi: 10.1088/2053-1591/aadc16

7. Z. Hua, J. Yang, T. Wang, G. Liu and G. Zhang, Transparent surface with reversibly switchable wettability between superhydrophobicity and superhydrophilicity, Langmuir, 2013, 29, no. 33, 10307-10312. doi: $10.1021 / \mathrm{la} 402584 \mathrm{v}$

8. G. Wang and T.Y.Zhang, Easy route to the wettability cycling of copper surface between syperhydrophobicity and superhydrophilicity, ACS Appl. Mater. Interfaces, 2012, 4, 273-279. doi: 10.1021/AM2013129

9. S. Patra, S. Sarkar, S.K. Bera, G.K. Paul and R. Ghoch, Influence of surface topography and chemical structure on wettability of electrodeposited $\mathrm{ZnO}$ thin films, Appl. Phys., 2010, 108, 083507. doi: 10.1063/1.3615932

10. V.I. Vigdorovich, E.Yu. Shel, L.E. Tsygankova, N.V. Shel and A.A. Uryadnikov, The effect of the concentration of hydrogen ions on the kinetics of partial electrode reactions on steels with a superhydrophobic surface in acid chloride environments, Korroz.: mater., zashch. (Corrosion: materials, protection), 2017, no. 4, 1 (in Russian).

11. L.B. Boinovich, A.M. Emel'yanenko, A.D. Modestov, A.G. Domantovsky and K.A. Emelyanenko, Not simply repel water: the diversified nature of corrosion protection by superhydrophobic coatings, Mendeleev Commun., 2017, 27, no. 3, 254256. doi: 10.1016/j.mencom.2017.05.012

12. V.I. Vigdorovich, L.E. Tsygankova, A.A. Uryadnikov, N.V. Shel, L.G. Knyazeva, and E.D. Tanygina. The Effect of Nanocomposite Superhydrophobic Coating on Corrosion and Kinetics of Electrode Processes on Steel in $0.5 \mathrm{M} \mathrm{NaCl}$ Solution, Protect. Met. Phys. Chem. Surf., 2017, 53, no. 7, 1259-1264. doi: 10.1134/S2070205117070176

13. E. Abelev, T.A. Ramanarayanan and S.L. Bernasek, Iron corrosion in $\mathrm{CO}_{2}$ /brine at low $\mathrm{H}_{2} \mathrm{~S}$ concentrations: an electrochemical and surface science study, J. Electrochem. Soc., 2009, 156, no. 9, C331-C339. doi: $\underline{10.1149 / 1.3160373}$ 
14. V.I. Vigdorovich and S.A. Zakurnaev. Evaluation of the contributions of the polysulfide film and inhibitor in protecting steel against hydrogen sulfide corrosion, Korroz.: mater., zashch. (Corrosion: materials, protection), 2009, no. 2, 17-22 (in Russian).

15. J. Ou, M. Liu, W. Li, M. Xue and C. Li, Corrosion behavior of superhydrophobic surfaces of Ni alloys in $\mathrm{NaCl}$ solutions, Appl. Surf. Sci., 2012, 258, no. 10, 4724-4728. doi: $\underline{10.1016 / j . a p s u s c .2012 .01 .066}$ 